\title{
Treatment Pattern of dermatophytosis at the outpatient clinic of a tertiary healthcare hospital of Chhattisgarh, Central India
}

\author{
Vinod Koshley ${ }^{1}$, Ajay K. Halwai ${ }^{2 *}$, Shubha B. Koshley ${ }^{3}$, Praveen K. Kurrey ${ }^{4}$, Shikha Jaiswal ${ }^{5}$ \\ $\mathbf{1 , 2 , 4 , 5}$ Assistant Professor, ${ }^{3}$ Medical Consultant, ${ }^{\mathbf{1}}$ Dept. of Dermatology, ${ }^{\mathbf{2}, 5}$ Dept. of Pharmacology, ${ }^{4}$ Dept. of Anatomy, ${ }^{\mathbf{1 , 2 , 4 , 5}} \mathrm{Pt}$. \\ Jawahar Lal Nehru Memorial Medical College, Raipur, Chattisgarh, ${ }^{3}$ Medical Dispensary National Institute of Technology, \\ Raipur, Chhattisgarh, India
}

*Corresponding Author:

Email: drgupta365@gmail.com

\begin{abstract}
Background: in the recent past dermatophytosis are being highly prevalent, main culprit behind is inappropriate use of antifungal agents and self-medications which is leading to exponential rise in global burden superficial fungal infections, and antifungal drug resistance. Clinician's management pattern data collection on time to time to have a check on the resistance/sensitivity pattern of the commonly prescribed antifungals in clinical grounds is important.

Aims and objectives: The present study was to describe the pattern of antifungal drug prescription and self-medication for common superficial fungal infections of skin in dermatology OPD in tertiary care hospital of Chhattisgarh.

Materials and Methods: Current study was a cross sectional unicentric study conducted at Dermatology OPD of Pt J.N.M. Medical College Raipur, the data collection for this observational study was undertaken for a period of six months. All patients attending the dermatology OPD with tinea infections were included in the study. This study was designed to record parameters include information related to demographic, disease profile, medications prescribed, number of drugs, dosage $\&$ duration were reported. Self medication pattern was also being observed during this study.

Results: A total of 17286 patients attended dermatology OPD and 42\% patients were suffering from tinea. The most common fungal infection was Tinea cruris 55.07\%, the commonest treatment pattern was Combination of oral \&Topical therapy $92.15 \%$. Most frequently prescribed combination was fluconazole plus itraconazole along with Clotrimazole cream was seen in $64.45 \%$, commonest anti-fungal agents were the azoles; amongst which clotrimazole (67.04\%)were the commonest. Commonly prescribed individual antifungal was oral Fluconazole $73.11 \%$. The self-medication prevalence for dermatophytosis was $62.26 \%$. Self-medication drugs were mainly topical (creams) FDC of antifungal and steroids. Around 76\% of the self-medication information was obtained from the chemists.
\end{abstract}

Keywords: Dermatophytosis, Antifungal agents, Self-medication, Itraconazole.

\section{Introduction}

In the past few years dermatophytosis has undergone a sea change in its clinical pattern and currently there is alarming situation of unprecedented increased incidence as well as the prevalence of superficial dermatophytosis is seen in India. The standard treatment recommendations which we have been following from the Western and Indian literature are no longer valid or even realistic ${ }^{1-3}$ such as dermatophytoses, identifying and understanding various factors related to host, environment, and agent are essential. At the same time, it is crucial to analyze whether the clinical failure of antifungal therapy is due to recurrence and/or resistance. The development of any management strategy to treat dermatophytoses must take into account of these factors. ${ }^{4}$ Despite the increasing prevalence of cutaneous dermatophytosis across the world, and especially in tropics, research in this area has often been neglected. In fact, one has to go back nearly two decades to find guidelines on the management of tinea corporis and cruris (by the American Academy of Dermatology) ${ }^{5}$ and these at best, appear inadequate in today's world. The more recent guidelines published by the British Association of Dermatology and in the British Medical Journal have largely focused on tinea capitis and tinea unguium with scarce reference to tinea corporis/cruris. ${ }^{6-8}$ Updated Cochrane reviews on the use of topical therapy in tinea corporis, cruris, and pedis, and few on oral therapies have helped to bridge this knowledge gap but still well designed trials, national and/ or international evidence based guidelines and recommendations on the dose and duration of the use of systemic antifungals in tinea corporis/ cruris are conspicuous by their absence. ${ }^{9-11}$ Drug implies very critical role in the improvement of human health and well-being. Periodic prescription audit is a way to control irrational prescribing. It minimize overuse and misuse of drugs, enhances the therapeutic efficacy, minimize the adverse effects and to plan essential drug selection, optimizes the cost of the therapy, provide useful feedback to the clinician and estimate the drug need of the community, thus have a favourable impact on the standards of treatment.

\section{Materials and Methods}

This was a record based, observational, study conducted at Pt. J.N.M Medical College Raipur, an academic tertiary care hospital in Chhattisgarh. It covered six month period from July 2017 to December 2017. Outpatients of all ages and both genders attending opd with superficial fungal infections and receiving antifungal medications during the study 
period were included. The demographic information of the patients (age, gender, symptoms, diagnosis) and drugs information (name, class, dose, treatment duration, topical or systemic and frequency of administration,) was noted. Self-medication Indices such as: Frequency of self medication, Drugs frequently self-medicated, Source of information for self medication were evaluated too. These data were analyzed to evaluate the prescription pattern and rationality of the use of drugs in the treatment of tinea infections.

\section{Result and Observations}

Total 17286 patients were attended dermatology opd and $7260(42 \%)$ patients were suffering from tinea .Out of them $4138(57 \%)$ patients were males and $3122 / 7260$ (43\%) were females [Table 1], which shows greater prevalence of tinea in males similar male preponderance was seen in studies done by Siddhartha A. Kamerkar, et al and Vegada BN et al. ${ }^{12-13}$ In the disease spectrum tinea cruris was the commonest and seen in $3998(55.07 \%)$ patients followed by tinea corporis 2846(39.20\%) [Table 2] , Kak, et al also reported the similar observation in his study as tinea corporis $(44.3 \%)$ followed by tinea cruris $(38.2 \%)$ as the most common clinical pattern. ${ }^{14}$

Oral fluconazole was the most common drug prescribed amongst the oral formulations whereas topical clotrimazole was the most common drug prescribed amongst the topical formulations which may be because availability of Flucanazole free supply in hospital pharmacy Minocha and Narwane conducted studies also showed that most common oral antifungal agent was fluconazole due to availability in hospital pharmacy. ${ }^{15-16}$

During entire study period common treatment pattern observed was combination therapy of Topical along with systemic antifungal therapy and seen in $6690(92.15 \%)$ depicting severity of disease as shown in Table 3, Vegada BN et al, also observed similar majority $(95.92 \%)$ of combination of a topical with an oral antifungal drugs in his study. ${ }^{13}$ In our study majority of prescriptions were for combination of three agents consisting of oral and topical formulation. It consisted mainly of oral fluconazole/ itraconazole, oral antihistamine cetrizine/hydroxyzine and topical Clotrimazole [Table 5-6]. Regarding treatment pattern, drugs prescribed -In tinea cases were, oral fluconazole in $2305(31.75 \%)$ followed by itraconazole in combination with Flucanazole 2128 (29.31\%) were the commonest whereas flucanazole along with terbinafine was seen in $867(11.94 \%)$ [Table 5]. Systemic Flucanazole is being commonest prescribed antifungal drug was also seen in studies by Vegada BN et al, Kamerkar et al and Khalid A et al ${ }^{12,13,17}$ in their study. Rajathilagam conducted a study also demonstrated that fluconazole (63\%) was most commonly used oral antifungal agent. ${ }^{18}$

In an study, Vishal P Giri et al reported systemic polytherapy consisting of Terbinafine and levocetrizine in $50.64 \%$ patients as commonest in his study (19). In another study by $D e b P$ et al the most commonly prescribed individual antifungal was oral Terbinafine $(64.81 \%)$ and topical was eberconazole $(58.49 \%){ }^{20}$

In our study we observed systemic polytherapy consist simultaneous use of itraconazole \& fluconazole as commonest, instead of Terbinafine showing gradual shifting of favor in oral antifungals from Fluconazole to terbinfine and from Terbinafine to itraconazole recently making itraconazole as most favoring oral antifungal now a days.

In topical antifungals the most commonly prescribed drugs were clotrimazole $(67.04 \%)$ followed by miconazole (17.07\%) and these were free supply in hospital pharmacy and after these available creams luliconazole $(6.93 \%)$ \& terbinafine $(6.32 \%)$ were commonest [Table 4] making luliconazole as new favored topical antifungal drug. Kamerkar, et al and Vegada BN et al, also reported Clotrimazole as commonest topical in their studies. ${ }^{12-13}$

Regarding usage of antihistamines in this study shows cetrizine was commonest $(66.43 \%)$ in sedative type and fexofenadine was commonest in non sedative type of antihistaminic (5.76\%) shown in Table 6. Self medication has become a common health care practice among the population. This has constantly become popular because; easy Over the Counter availability at same time peoples have become increasingly aware of the drugs and their brand names. The drug sensitive fungal pathogens have gradually developed resistance thus making it progressively grim to treat even the most modest fungal infections. It has been documented that injudicious use of Steroidal creams has resulted into the worsening of the existing lesions and making it difficult to treat them. The prevalence of self-medication among patients was seen in $56.60 \%$ (4109). Most of the drugs for self-medication were topical (creams) fixed drug combination of antifungal and steroids and around $76 \%$ of the self-medication information was obtained from the chemists and almost similar self medication pattern was noted by Pooja Deb et al in their study. ${ }^{20}$

Table 1: Patients Distribution

\begin{tabular}{|l|l|l|l|}
\hline Total Patients & 17286 & Tinea Patients & $7260 / 17286(42 \%)$ \\
\hline Male & $9858(57.03 \%)$ & Male & $4138 / 7260(57 \%)$ \\
\hline Female & $7428(42.97 \%)$ & Female & $3122 / 7260(43 \%)$ \\
\hline
\end{tabular}


Table 2: Disease Distribution

\begin{tabular}{|l|c|c|}
\hline Type of fungal infection & Total Numbers & Percent \% \\
\hline T. Cruris & 3998 & $55.07 \%$ \\
\hline T. Corporis & 2846 & $39.20 \%$ \\
\hline T.Faciei & 248 & $3.42 \%$ \\
\hline T.Manum/Pedis & 168 & $2.31 \%$ \\
\hline
\end{tabular}

Table 3: Treatment pattern during entire study period

\begin{tabular}{|l|c|c|}
\hline Treatment Modalities & No. of patients & Percent \\
\hline Combination therapy & 6690 & $92.15 \%$ \\
Oral + Topical & & \\
\hline Monotherapy & 570 & $7.85 \%$ \\
Topical therapy & 531 & $7.31 \%$ \\
Oral therapy & 39 & $0.54 \%$ \\
\hline
\end{tabular}

Table 4: Topical drugs in Tinea Patients

\begin{tabular}{|l|l|l|}
\hline \multicolumn{1}{|c|}{ Drug } & No of patients & Percent \\
\hline Clotrimazole & 4867 & $67.04 \%$ \\
\hline Miconazole & 1239 & $17.07 \%$ \\
\hline Terbinafine & 459 & $6.32 \%$ \\
\hline Luliconazole & 503 & $6.93 \%$ \\
\hline Eberconazole & 57 & $0.76 \%$ \\
\hline Clotrimazole+ Betamethasone & 135 & $1.86 \%$ \\
\hline
\end{tabular}

Table 5: Systemic Drugs in Tinea Patients

\begin{tabular}{|l|c|c|}
\hline \multicolumn{1}{|c|}{ Oral Antifungal Agents } & $\begin{array}{c}\text { No. of patients } \\
(\mathbf{6 6 9 0 + 2 6 = 6 7 1 6 )} \mathbf{9 2 . 5 \%}\end{array}$ & Percent \\
\hline Fluconazole alone & 2305 & $31.75 \%$ \\
Fluconazole + Terbinafine & 867 & $11.94 \%$ \\
Fluconazole + itraconazole & 2128 & $29.31 \%$ \\
Fluconazole + ketoconazole & 8 & $0.11 \%$ \\
Fluconazole + Griseofulvin & 0 & $0 \%$ \\
\hline Itraconazole alone & 568 & $7.82 \%$ \\
Itraconazole +ketoconazole & 21 & $0.29 \%$ \\
\hline Ketoconazole alone & 72 & $0.99 \%$ \\
\hline Terbinafine alone & 438 & $6.03 \%$ \\
Terbinafine + itraconazole & 309 & $4.25 \%$ \\
\hline Griseofulvin & 0 & $0 \%$ \\
\hline
\end{tabular}

Table 6: Oral Antihistaminic Drugs in Tinea Patients

\begin{tabular}{|l|c|c|}
\hline Antihistamine Drug & No of patients & Percent \\
\hline Cetrizine & 4823 & $66.43 \%$ \\
\hline Levocetrizine & 827 & $11.39 \%$ \\
\hline Fexofenadine & 418 & $5.76 \%$ \\
\hline Hydroxyzine & 937 & $12.90 \%$ \\
\hline Polaramine & 201 & $2.77 \%$ \\
\hline Desloratidine & 54 & $0.74 \%$ \\
\hline
\end{tabular}

\section{Conclusion}

There is gradual shift of management pattern from flucanazole to terbinafine and then from terbinafine to itraconazole have been observed and this change in management patterns of tinea which are the most frequently encountered, are the effect of freely available irrational fixed drug combination creams. Fixed drug combination (FDC) creams are usually a combination three drugs comprising potent steroid like clobetasol propionate, antifungal, and antibacterial in the product. These FDC creams are available over the counter, buying over the counter and grossly abused by applying at will for weeks, months and sometimes for years, which was prescribed by the general practitioners or quacks or suggested \& sold by the pharmacist. This is the most dreadful situation where we are fallen in the recent times which lead to chronic, treatment resistant dermatophytosis which is causing mayhem in India. 
There is a tremendous need for well designed studies for various issues pertaining to the dermatophytosis scenario in India.

Funding: No funding sources.

Conflict of interest: None declared.

\section{References}

1. Hay RJ, Ashbee HR. Fungal infections. In: Griffiths CE, Barker Verma and Madhu: Epidemic of Superficial dermatophytosis in India. Indian J Dermatol 2017;62(3):235

2. J, Bleiker T, Chalmers R, Creamer D, editors. Rook's Textbook of Dermatology. 9th ed., Vol. II. West Sussex: Wiley Blackwell; 2016. p. 945.

3. Schieke SM, Garg A. Superficial fungal infection. In: Goldsmith LA, Katz SI, Gilchrest BA, Paller AS, Leffel DJ, Wolff K, editors. fitzpatrick's Dermatology in General Medicine. 8th ed., Vol. II.New York: The McGraw-Hill Companies; 2012. p. 2294.

4. Manjunath Shenoy M, Suchitra Shenoy M. Superficial fungal infections. In: Sacchidanand S, Oberoi C, Inamdar AC, editors. IADVL Textbook of Dermatology. 4th ed., Vol. I. Mumbai: Bhalani Publishing House; 2015. p. 459516.

5. Shivanna R, Inamadar AC. Clinical failure of antifungal therapy of dermatophytoses: Recurrence, resistance, and remedy. Indian J Drugs Dermatol 2017;3:1-3.

6. Drake LA, Dinehart SM, Farmer ER, Goltz RW, Graham GF, Hardinsky MK, et al. Guidelines of care for superficial mycotic infections of the skin: Tinea corporis, tinea cruris, tinea faciei, tinea manuum, and tinea pedis. Guidelines/Outcomes Committee. American Academy of Dermatology. J Am Acad Dermatol 1996;34(2 Pt 1):282-6.

7. Ameen M, Lear JT, Madan V, Mohd Mustapa MF, Richardson M. British Association of Dermatologists' guidelines for the management of onychomycosis 2014. Br J Dermatol 2014;171:937-58.

8. Fuller LC, Barton RC, Mohd Mustapa MF, Proudfoot LE, Punjabi SP,Higgins EM. British Association of Dermatologists' guidelines for the management of tinea capitis. Br J Dermatol 2014;171:454-63.

9. Moriarty B, Hay R, Morris-Jones R. The diagnosis and management of tinea. BMJ 2012;345:e4380.

10. El-Gohary M, van Zuuren EJ, Fedorowicz Z, Burgess H, Doney L, Stuart B, et al. Topical antifungal treatments for tinea cruris and tinea corporis. Cochrane Database Syst Rev 2014;8:CD009992.

11. Crawford F, Hollis S. Topical treatments for fungal infections of the skin and nails of the foot. Cochrane Database Syst Rev 2007;( 3):CD001434.

12. Bell-Syer SE, Khan SM, Torgerson DJ. Oral treatments for fungal infections of the skin of the foot. Cochrane Database Syst Rev 2012;10:CD003584.

13. Siddhartha a.kamerkar, Prescription pattern and the cost analysis of tinea and acne patients in the dermatology department of a tertiary care teaching hospital.www.rajournals.in 2016;2(2):416-23

14. Vegada BN, Karelia BN, Singh AP, Drug utilization study of antifungal agents used in department of skin \& v.d. Of a tertiary care teaching hospital. Int J Pharm Sci Rev Res 2015;34(1):118-21.

15. Kak Surendran,Ramesh M Bhat,A clinical and mycological study of dermatophytic infections. Indian $J$ Dermatol 2014;59(3):262-67.

16. Minocha KB, Bajaj K, Gupta K GM, A ClinicoPharmacological Study Of Out-Patient Prescribing Pattern Of Dermatological Drugs In An Indian Tertiary Hospital, Indian J Pharmacol 2000;32:384-85.

17. Narwane SP, Patel TC, Shetty, YC, Chikhalkar SB. Drug utilization and cost analysis for common skin in dermatology opd of an Indian tertiary care hospital - A Priscription survey. Br J Pharm Res 2011;1(1):9-18

18. Khalid A. Al Balushi, Mohammed A. Alzaabi, Fatma Alghafri. Prescribing pattern of antifungal medications at a tertiary care hospital. Oman J Clin Diagnostic Res 2016;10(12):fc27-fc30

19. Rajathilagam T, Sandozi T, Raagopalan V, A Study Of Prescribing Pattern Of Antifungal Drugs In Hospital, IJBPR 2012;3(8):968-73.

20. Vishal P Giri, Om P Giri, Drug prescribing pattern in dermatophytosis at the medical outpatient clinic of a tertiary healthcare in karnataka, India: 10.5455/medscience.2015.04.8250

21. Pooja deb, Ipseeta Mohanty, Indu Slathia, Vandana Verma. Drug utilisation and self medication pattern of anti-fungal drugs in dermatology outpatient department of a tertiary care hospital. Int J Basic Clin Pharmacol 2017;6(9):2189-92.

How to cite this article: Koshley V., Halwai A., Koshley S., Kurrey P., Jaiswal S. Treatment Pattern of dermatophytosis at the outpatient clinic of a tertiary healthcare hospital of Chhattisgarh, Central India. Indian J Clin Exp Dermatol 2018;4(4):327-30. 